\title{
Physiological and Perceived Exertion Responses during International Karate
}

\author{
Montassar Tabben ${ }^{* 1,2 A C D E F G}$; Rim Sioud ${ }^{1 \mathrm{ABFG}}$; Monoem Haddad ${ }^{1,3 \mathrm{BDEG}}$; Emerson Franchini $^{\text {4ACDEFG }}$; Anis Chaouachi $^{{ }^{1 \mathrm{ABFG}}}$; \\ Jeremy Coquart $^{2 \mathrm{ABFG}}$; Helmi Chaabane ${ }^{5 \mathrm{BEFG}}$; Karim Chamari ${ }^{1,6 \mathrm{ABCEFG}}$; Claire Tourny-Chollet $^{2 \mathrm{CDEFG}}$
}

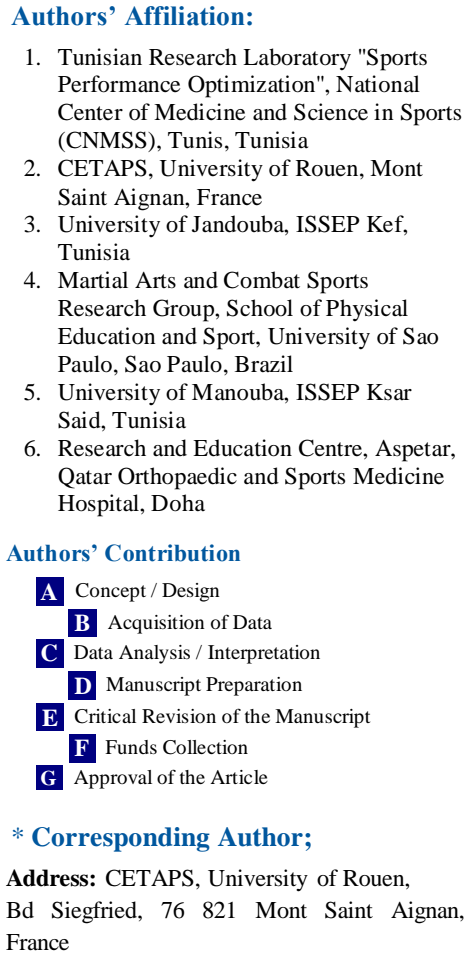

1. Tunisian Research Laboratory "Sports Performance Optimization", National Center of Medicine and Science in Sports (CNMSS), Tunis, Tunisia

2. CETAPS, University of Rouen, Mont Saint Aignan, France

3. University of Jandouba, ISSEP Kef, Tunisia

4. Martial Arts and Combat Sports Research Group, School of Physical Education and Sport, University of Sao Paulo, Sao Paulo, Brazil

5. University of Manouba, ISSEP Ksar Said, Tunisia

6. Research and Education Centre, Aspetar, Qatar Orthopaedic and Sports Medicine Hospital, Doha

$$
\begin{aligned}
& \text { Authors' Contribution } \\
& \text { A Concept / Design } \\
& \text { C D Aata Analysis / Interpretation } \\
& \text { E Critical Revision of the Manuscript } \\
& \text { F Funds Collection } \\
& \text { G Approval of the Article }
\end{aligned}
$$

* Corresponding Author;

Address: CETAPS, University of Rouen, Bd Siegfried, 76821 Mont Saint Aignan, France

E-mail: montakarate@live.fr

Received: Feb 15, 2013

Accepted: Aug 2, 2013

Available Online: Sep 3, 2013

\begin{abstract}
Purpose: Investigate the physiological responses and rating of perceived exertion (RPE) in elite karate athletes and examine the relationship between a subjective method (Session-RPE) and two objective heart-rate (HR)-based methods to quantify training-load (TL) during international karate competition.
\end{abstract}

Methods: Eleven karatekas took part in this study, but only data from seven athletes who completed three matches in an international tournament were used (four men and three women). The duration of combat was 3 min for men and $2 \mathrm{~min}$ for women, with $33.6 \pm 7.6 \mathrm{~min}$ for the first interval period (match 1-2) and 14.5 $\pm 3.1 \mathrm{~min}$ for the second interval period (match 2-3). HR was continuously recorded during each combat. Blood lactate [ $\left.\mathrm{La}^{-}\right]$and (RPE) were measured just before the first match and immediately after each match.

Results: Means total fights time, HR, \% HRmax, [La] ${ }^{-}$and session-RPE were 4.7 $\pm 1.6 \mathrm{~min}, 182 \pm 9 \mathrm{bpm}, 91 \pm 3 \%, 9.02 \pm 2.12 \mathrm{mmol}^{-\mathrm{L}^{-1}}$ and $4.2 \pm 1.2$, respectively. No significant differences in \% HRmax, [ $\left.\mathrm{La}^{-}\right]$, and RPE were noticed across combats. Significant correlations were observed between RPE and both resting HR $(r=0.60 ; P=0.004)$ and mean $H R(r=0.64 ; P=0.02)$, session-RPE and Banister training-impulse (TRIMP) $(\mathrm{r}=0.84 ; \boldsymbol{P}<0.001)$ and Edwards TL $(r=0.77 ; P<0.01)$.

Conclusion: International karate competition elicited near-maximal cardiovascular responses and high $\left[\mathrm{La}^{-}\right]$. Training should therefore include exercise bouts that sufficiently stimulate the zone between 90 and $100 \%$ HRmax. Karate coaches could use the RPE-method to follow competitor's competition loads and consider it in their technical and tactical training.

Key Words: Martial Arts; Heart Rate; Blood Lactate; Rating of Perceived Exertion

\section{INTRODUCTION}

$\mathrm{C}$ ombat sports take a significant place in sport today and karate represents one of the most popular combat sports worldwide ${ }^{[1]}$. Karate kumite is a semi-contact fighting event, i.e. the fighters perform techniques towards the opponent with open force in body but with light touch in face. Karate requires a high level of physical, physiological, complex technical skills and tactical excellence for success ${ }^{[2]}$.
Modern karate consists of numerous repetitions of high intensity actions per fight lasting 1-3 s each, separated by low-intensity hopping-stepping movements $(18 \pm 6 \mathrm{~s})$ and short referees' breaks $(9 \pm 6 \mathrm{~s}){ }^{[3]}$. Single defensive or offensive techniques last $0.3 \pm 0.1$ to $1.8 \pm 0.4 \mathrm{~s}$ for the shortest and longest duration actions, respectively. The definition of the metabolic profile of any sports activity is essential for the determination of the functional conditions necessary for good performance. During continuous activities, metabolic cost depends on the 
intensity and duration of exercise. Alternatively, during intermittent activities, other factors such as the ratio between the duration of exercises and rest become important, a fact that renders the definition of metabolic cost much more complex in these activities ${ }^{[1]}$. Overall karate fighting is ranked as a high intensity event ${ }^{[1]}$. Lehmann and Jedliczka ${ }^{[2]}$ have suggested that anaerobic metabolism is considered as the predominant source of energy in this sport. On the other hand, Beneke et al ${ }^{[3]}$ have investigated the energetics of karate kumite based on measures of aerobic and anaerobic metabolism during simulated fighting, and concluded that the aerobic metabolism is predominant during this activity, although the decisive actions (i.e. attacks and defense techniques) are maintained mainly via the anaerobic lactic system activation. The abovementioned studies indicate that determinant actions in karate kumite are based on activities that require a high metabolic rate. A markedly elevated accumulation of blood lactate ([La]) has been observed after karate bouts competition in elite athletes ${ }^{[5]}$. Owing to the needs of aerobic and anaerobic demands of karate competition, elite class karate athletes are usually prescribed a mixed training regime that elicits adaptation in both energy pathways. The physiological profile of elite competitors has been presented recently ${ }^{[1]}$ showing the needs of developing both metabolisms in karate athletes.

In terms of the physiological requirements of official competition, relatively little direct evidence is available. Indeed, to the best of our knowledge the studies available on competitive karate-kumite have investigated energetic profile during simulated sparring matches ${ }^{[3,6]}$. In contrast to the behavioral indicators discussed above that suggest a high anaerobic demand in karate competition, these studies found that the postfights $\left[\mathrm{La}^{-}\right]$values were very low. These data are believed to be limited in their generalizability due to the measurement equipment worn during the simulated fights, which place limitations on the movement capabilities of the karate athletes. Hence, techniques for assessing energetics that do not place limitations on movement capabilities of athletes need to be explored. Furthermore, one of the most important challenges confronting coaches and athletes is to understand the main physiological factors contributing to the success or failure of a karateka during actual competition. Since simulated competitions cannot represent official competitions and owing to the fact that physiological responses of authentic international competition have never been investigated, the evaluation of the physiological responses of international karate competition represents a key gap in the current understanding of karate athlete competition performance and its preparation.

During official competition, competitors could perform several matches in the same day prior to undertaking a final's match. Thus, it is important to understand the impact of fighting in dynamic terms over the course of a competition on the physiological stress of karate athletes. Additionally, coaches need reliable and easily measurable variables to monitor the training-load (TL) imposed on the athletes during competition. Recently, the rating of perceived exertion (RPE) method has been investigated and proposed as a valid tool to quantify the internal training load in different sports ${ }^{[7]}$. In addition, this method reflects a high utility in that it is simple to apply (requiring little technical expertise), non-invasive and individually specific (useful for repeated measures), and inexpensive. Generally, to establish the construct validity of the RPE method, many studies have investigated its relationship with at least two HR-based methods ${ }^{[8-10]}$. Among these objective methods, Banister and Edwards's methods are the most useful ${ }^{[8-}$ ${ }^{11]}$. Thus, the study of the interaction between the RPE method and the different objective methods during official karate competition can be relevant. However, whilst there has been no information concerning the validity of RPE to quantify the internal load during official karate kumite competitions, there is considerable evidence to suggest that RPE method could contribute to a more accurate quantification of how the athlete is responding to each match during official karate competition.

Therefore, the objectives of the present study were: 1) to analyze the physiological responses of athletes during an official international karate competition, by determining heart rate (HR), pre and post $\left[\mathrm{La}^{-}\right]$, and RPE, and; 2) to establish the relationship between a subjective (session-RPE) and two objective (training impulse [Banister TRIMP]) and summated heart-rate- 
zone (Edwards TL) methods of quantifying TL and explain characteristics of the variances in these relationships.

\section{METHODS AND SUBJECTS}

\section{Participants}

Eleven karatekas, all black belts and internationally ranked athletes from national karate team, volunteered to take part in the study. During an official competition, if the competitor loses, he/she will be eliminated from the competition. Thus, only athletes who had won the first 3 matches were selected to study the selected physiological variables. This number of matches has been chosen to provide relevant information for each athlete and to allow the analysis of a moderate number of athletes during internationallevel official competition. During the event only four men (age $22.5 \pm 1.2$ yrs, body mass $76.2 \pm 8.5 \mathrm{~kg}$, body fat percentage $7.5 \pm 1.6 \%$, height $1.83 \pm 0.06 \mathrm{~m}$, competition experience $5 \pm 1$ yrs) and three women (age $22.3 \pm 0.3$ yrs, body mass $56.9 \pm 6.9 \mathrm{~kg}$, body fat percentage $18.4 \pm 4.6 \%$, height $1.70 \pm 0.05 \mathrm{~m}$, competition experience $5 \pm 1 \mathrm{yrs}$ ) have been included in the study based on the inclusion criteria that they succeeded in winning the first three matches of the competition. All participants had at least seven karate training sessions per week and had been competing in international competitions for at least three years. All athletes received both verbal and written explanations about the aim and procedures of the study. The Ethics Committee of the National Centre of Medicine and Sciences in Sports has given institutional approval for the study and all subjects have signed a written informed consent before participating to the experiment.

\section{Procedures}

Anthropometric Measurements: The height, body mass, and skinfold thickness were measured with a wall stadiometer (model 220, Seca, Hamburg, Germany), a calibrated scale (TBF 543, Tanita, Tokyo, Japan), and a skinfold caliper (HSK-B1, Body Care,
Warwickshire, UK).

Maximal test: Two weeks before the competition, all athletes performed a maximal treadmill test. On entering the laboratory, subjects lay on a bench and rested for $15 \mathrm{~min}$. The lowest HR recorded during this period was considered as resting HR. Then, subjects ran on a flat treadmill (Ergo XELG 90; Woodway, Weil, Germany) for three minutes at $9 \mathrm{~km} / \mathrm{h}$. The speed was then increased by $1 \mathrm{~km} / \mathrm{h}$ every minute until exhaustion, which occurred within 10-15 min for all subjects. To determine $\mathrm{VO}_{2 \max }$ a respiratory gas exchange ratio higher than 1.1 was met by all athletes. The highest HR attained at exhaustion was recorded and was considered as maximal HR (HRmax). Cardiorespiratory variables were determined using a breath-by-breath system (ZAN 680; Messgerate, Oberthulba, Germany). HR was recorded using a Polar Team System HR monitor (Polar, Kempele, Finland).

Data collection: All participants competed in a seniorlevel international competition (International Karate Dutch Open, Rotterdam 2010). Twelve international teams took part on this tournament. The competition was held in a gymnasium on standard mats, and all qualifying, semifinal and final phases of the event occurred between 9:00 and 19:00 $\mathrm{h}$ of the same day. Only athletes who have won three matches during the competition were selected. Thus, each athlete performed a total of three matches. As duration of combat was of $3 \mathrm{~min}$ for men and 2 min for women, each male fought for $5.4 \pm 1.5$ and each female fought for $3.6 \pm 1.0 \mathrm{~min}$. Before $30 \mathrm{~min}$ of the first match each athlete performed an individual and free warm-up. Between matches, each athlete had chosen the suitable recovery type (passive and/or active). The mean inbetween combats recovery period was $33.6 \pm 7.6 \mathrm{~min}$ for the first interval period (between matches 1 and 2) and 14.5 $\pm 3.1 \mathrm{~min}$ for the second interval period (between matches 2 to 3 ). The data inclusion criteria were the successful measurement of $\mathrm{HR},\left[\mathrm{La}^{-}\right]$, and RPE across three matches of the competition. In total, the mean data included here represent 7 competitors during a total of 21 combats.

During competition, the Tunisian Karate Federation has allowed to record the HR for all their karate athletes. HR was recorded using Polar Team System HR monitors (Polar, Kempele, Finland) with HR 
recorded every $5 \mathrm{~s}$ for each combat. Competitors were familiarized with the HR monitors during a number of karate training activities (e.g. contact sparring) and sessions before their use during competition. They indicated that these HR monitors did not impede their movements or action patterns in any manner during the karate activities. Each HR polar transmitter/receiver belt was attached across the participants' chest under the body armor before each individual combat. Data were subsequently downloaded using Polar Precision Software (Version 4.0, Polar Electro Ltd.). The HR was expressed as a percentage of competitors' HRmax and classified into five intensity zones as identified by Edward ${ }^{[12]}$. The average percentage of time spent in each HR intensity zone was also calculated for each combat.

Blood samples for $\left[\mathrm{La}^{-}\right]$determination and RPE were taken in the sitting position on a chair one minute before the first match (pre value) and one minute after each match (post value). Blood samples were analyzed with the Lactate Pro Analyzer (Arkray, Tokyo, Japan) to determine $\left[\mathrm{La}^{-}\right]$. The validated French version of the category ratio-10 (CR-10) scale was used ${ }^{[13]}$ to measure RPE. This scale is used to transform athletes' perceptions of effort into numerical scores between 0 and $10^{[7]}$. Competitors were completely familiarized with the RPE scale ${ }^{[13]}$ before competition analysis.

Quantification of Combat Load: Three methods of combat load quantification were used (i.e. one subjective and two objective methods). Session-RPE (i.e. subjective method) was determined by multiplying accurate total combat duration ( $\mathrm{min}$ ) by the RPE score, as described by Foster et al. ${ }^{[7]}$ Banister training impulse (TRIMP) ${ }^{[14]}$ and Edwards TL ${ }^{[12]}$ (i.e. objective methods) were based on HR measurement. The Edwards TL determines the internal load by measuring a product of the accumulated training duration ( $\mathrm{min}$ ) of five HR zones by a coefficient related to each zone (50 to $<60 \%$ of HRmax $\times 1,60$ to $<70 \%$ of HRmax $\times 2,70$ to $<80 \%$ of HRmax $\times 3,80$ to $<90 \%$ of HRmax $\times 4,90-100 \%$ of HRmax $\times 5$ ) and then summing the results. Banister TRIMP is calculated using an exponential factor, as in the following formula:

Men: duration $\times($ HRex - HRrest $) /($ HRmax - HRrest $) \times 0.64 e^{1.92 x}$ Women: duration $\times($ HRex - HRrest $) /($ HRmax - HRrest $) \times 0.86 e^{1.67 x}$
Where $e=2.712, x=($ HRex-HRrest $) /($ HRmax - HRrest $)$. In this equation, HRrest=average HR during rest, HRex=average HR during exercise, and HRmax=maximal HR.

\section{Statistical Analysis:}

All data were assessed for normality using the ShapiroWilks test before analysis. Pearson Correlation coefficients (r) were adopted for relationship analysis. Matches' comparison was conducted using ANOVA one-way with repeated measurements. Mauchly test was used to test Sphericity or Compound Symmetry. Friedman's repeated-measures rank test was used to identify differences in the time spent in specific HR intensity zones. Post-hoc analysis included Wilcoxon's matched-pairs signed-ranks tests, with Bonferroni adjustment for multiple comparisons. All statistical procedures were performed using SPSS for Windows (Version 14.0, SPSS Ltd, Surrey, U.K.). Descriptive data are expressed as means \pm SD unless stated otherwise.

\section{RESULTS}

HRmax and $\dot{\mathrm{V}}_{2}$ max during the maximal laboratory treadmill test were $200 \pm 5 \mathrm{bpm}$ and $52.00 \pm 6.10$ $\mathrm{mL} / \mathrm{kg} / \mathrm{min}$, respectively, for the whole group (for women, $200 \pm 7 \mathrm{bpm}$ and $47.00 \pm 4.00 \mathrm{~mL} / \mathrm{kg} / \mathrm{min}$; for men, $201 \pm 5$ bpm and $56.25 \pm 3.83 \mathrm{~mL} / \mathrm{kg} / \mathrm{min}$, respectively).

Pre [La'] was $2.87 \pm 0.24$ mmol. $\mathrm{L}^{-1}$. Total time, HR, post [ $\left.\mathrm{La}^{-}\right], \mathrm{RPE}$, session-RPE, Edwards TL and Banister TRIMP responses of competition are presented in Table 1.

During karate competition, mean HR was $182 \pm 9$ bpm (first match, 181 \pm 10 -bpm; second match, 182 \pm 8 bpm; third match, 183 \pm 8 -bpm). HR was most frequently distributed between 90 and 100\% of HRmax. The percentage of time spent in each HR intensity zone was unaltered between matches (Fig. 1).

No significant differences were found for total time $\left(\mathrm{F}_{2.12}=0.15 ; P=0.9 ; \eta^{2}=0.02\right)$, heart rate $\left(\mathrm{F}_{2.12}=0.55\right.$; 
Table 1: Total time, physiological responses, perceived exertion and combat loads of seven competitors during a total of 21 international combats (data are mean \pm standard deviation)

\begin{tabular}{|c|c|c|c|c|c|c|c|c|c|}
\hline Matche & & $\begin{array}{l}\text { Total } \\
\text { time } \\
\text { (min) }\end{array}$ & $\begin{array}{c}\mathrm{HR} \\
(\mathbf{b p m})\end{array}$ & $\begin{array}{c}\% \\
\text { HRmax }\end{array}$ & RPE & $\begin{array}{l}\text { Session } \\
\text { RPE }\end{array}$ & $\begin{array}{l}\text { Banister } \\
\text { TRIMP }\end{array}$ & $\begin{array}{c}\text { Edwards } \\
\text { TL }\end{array}$ & $\begin{array}{c}\text { Lactate } \\
\left(\mathrm{mmol} . \mathrm{L}^{-1}\right)\end{array}$ \\
\hline \multirow{3}{*}{$\begin{array}{l}\text { Match } \\
1\end{array}$} & Women & $3.5(0.8)$ & $185(11)$ & $92(3)$ & 4. $3(0.5)$ & $1.2(2.5)$ & $11.5(1.1)$ & $17.0(3.0)$ & $8.9(3.1)$ \\
\hline & Men & $5.1(1.3)$ & 177 (9) & $88(3)$ & $3.3(0.4)$ & 17.7 (6.4) & $13.8(2.9)$ & $23.1(5.0)$ & $8.8(0.9)$ \\
\hline & All & $4.5(1.4)$ & 181(10) & $90(3)$ & $3.8(0.7)$ & $16.7(5.0)$ & $12.9(2.5)$ & $20.5(5.1)$ & $8.8(1.9)$ \\
\hline \multirow{3}{*}{$\begin{array}{l}\text { Match } \\
2\end{array}$} & Women & $3.0(0.9)$ & $185(10)$ & $92(3)$ & $4.5(0.5)$ & $13.9(5.5)$ & $10.2(3.5)$ & $14.9(4.5)$ & $8.9(2.4)$ \\
\hline & Men & $5.7(1.0)$ & 179 (7) & $89(4)$ & $4.0(1.4)$ & $22.8(8.8)$ & $16.3(3.1)$ & $26.0(4.16)$ & $9.1(3.0)$ \\
\hline & All & $4.6(1.7)$ & $182(8)$ & $91(4)$ & $4.2(1.1)$ & $19.1(8.5)$ & $13.7(4.4)$ & $21.3(7.1)$ & $9.0(2.6)$ \\
\hline \multirow{3}{*}{$\begin{array}{l}\text { Match } \\
\mathbf{3}\end{array}$} & Women & $4.3(1.1)$ & $185(9)$ & $92(2)$ & $5.3(1.5)$ & $24.0(12.5)$ & $14.6(4.20$ & $20.4(4.9)$ & $10.0(2.0)$ \\
\hline & Men & $5.3(2.3)$ & $181(8)$ & $90(2)$ & $4.1(1.7)$ & $22.9(12.0)$ & $15.4(6.3)$ & 24.4 (9.7) & $8.4(2.1)$ \\
\hline & All & $4.9(1.8)$ & $183(8)$ & $91(3)$ & $4.6(1.7)$ & $23.4(11.2)$ & $15.1(5.1)$ & $22.7(7.8)$ & $9.2(2.1)$ \\
\hline \multirow{3}{*}{ Mean } & Women & $3.6(1.0)$ & 185 (8.7) & $92(2)$ & $4.7(0.9)$ & $17.7(8.4)$ & $12.1(3.4)$ & $17.4(4.4)$ & $8.8(0.9)$ \\
\hline & Men & $5.4(1.5)$ & $179(7)$ & $89(3)$ & $3.8(1.2)$ & $21.2(8.8)$ & $15.1(4.1)$ & $24.5(6.2)$ & $8.8(2.0)$ \\
\hline & All & $4.7(1.6)$ & $182(9)$ & $91(3)$ & $4.2(1.2)$ & 19.7 (8.7) & $13.9(4.1)$ & $21.5(6.5)$ & $9.0(2.1)$ \\
\hline
\end{tabular}

HR: Heart rate; \%HRmax: Percentage of maximum heart rate; RPE: Rating of perceived exertion; TRIMP: Training impulse; TL: Training load

$\left.P=0.6 ; \quad \eta^{2}=0.08\right), \quad \%$ HRmax $\quad\left(\mathrm{F}_{2.12}=0.36 ; \quad P=0.7 ;\right.$ $\left.\eta^{2}=0.06\right)$, RPE $\left(\mathrm{F}_{2.12}=1.37 ; P=0.3 ;{ }^{2}=0.19\right)$, sessionRPE $\left(\mathrm{F}_{2.12}=1.14 ; P=0.3 ; \eta^{2}=0.16\right)$, Banister TRIMP $\left(\mathrm{F}_{2.12}=0.63 ; P=0.5 ; \eta^{2}=0.10\right)$, Edwards TL $\left(\mathrm{F}_{2.12}=0.24\right.$; $\left.P=0.8 ; \eta^{2}=0.04\right)$ and $\left[\mathrm{La}^{-}\right]\left(\mathrm{F}_{2.12}=0.08 ; P=0.9 ; \eta^{2}=0.01\right)$ across matches performed during international competition.
Significant correlations were observed between RPE and resting HR $(\mathrm{r}=0.60 ; P=0.004)$, mean HR $(\mathrm{r}=0.64 ; P=0.02)$ and $\left[\mathrm{La}^{-}\right](\mathrm{r}=0.81 ; P<0.001)$, sessionRPE and Banister TRIMP ( $\mathrm{r}=0.84 ; P<0.001)$ and Edwards TL $(\mathrm{r}=0.77 ; P<0.01)$. Banister TRIMP and Edwards TL were also correlated with each other $(\mathrm{r}=0.95 ; P<0.001)$.

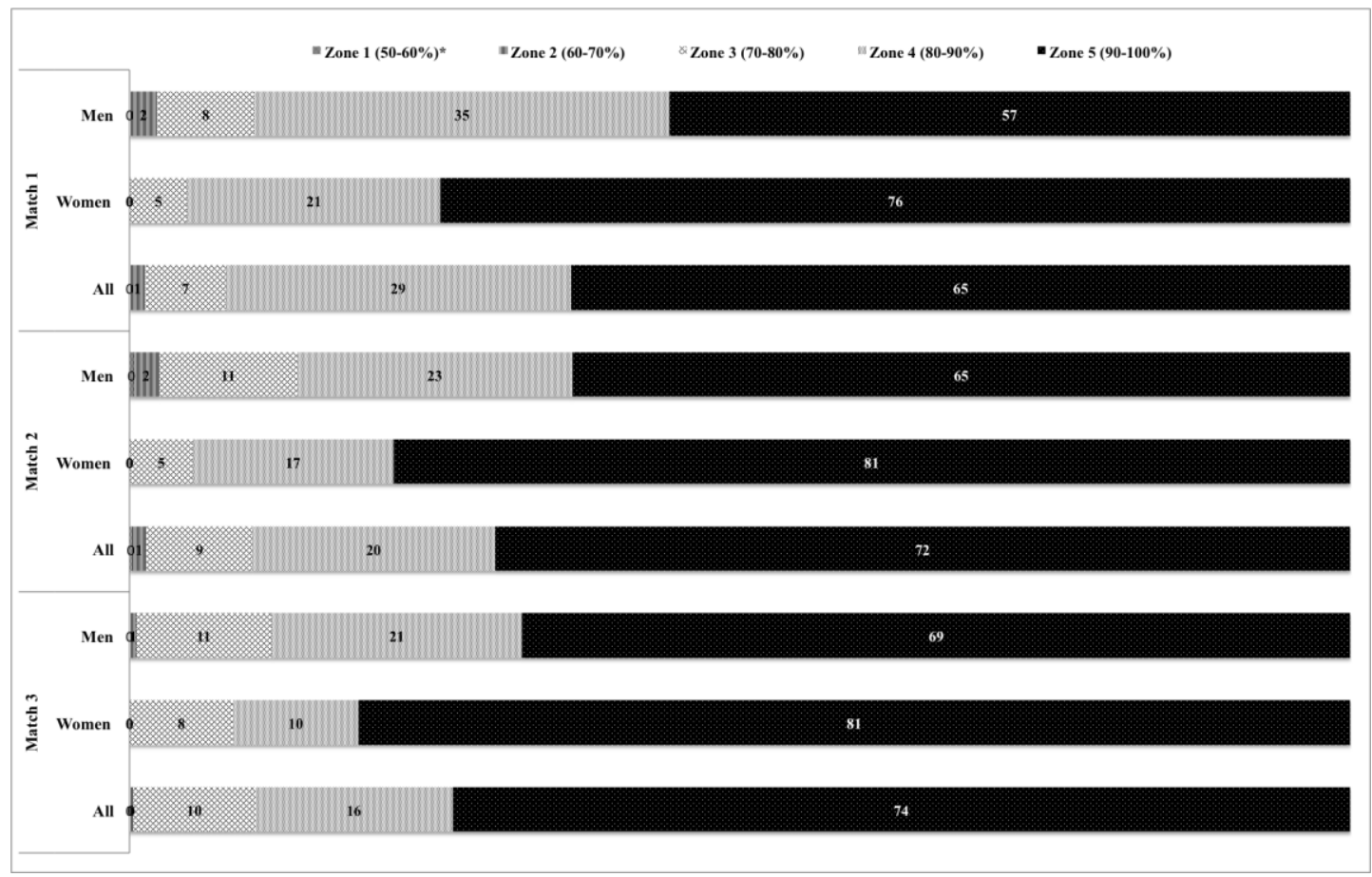

Fig. 1: Percentage of time spent in HR intensity zones across each match

* Zone 1 it does not appear since it was not solicited during the fight 


\section{DISCUSSION}

To the authors' knowledge, this is the first study to detail the physiological responses, RPE, and combat load during authentic international-level karate competition. The main findings of this study suggest that international karate competition is a high-intensity activity that elicits near-maximal cardiovascular responses and high $\left[\mathrm{La}^{-}\right]$concentrations. Additionally, these variables did not differ and stayed elevated after the different matches performed during the competition.

One important factor during high-intensity intermittent exercise is the athlete's aerobic fitness, as this ability is related to the recovery process after highintensity actions inside each combat as well as after each match ${ }^{[4]}$. $\mathrm{VO}_{2 \max }$, as an indicator of aerobic power, is frequently measured to evaluate karate athletes' aerobic profile. The $\mathrm{VO}_{2 \max }$ from our athletes was similar to that reported in Japanese and French elite karate athletes ${ }^{[15-17]}$ and in the range presented in a recent review about physiological profile of karate athletes ${ }^{[1]}$. In comparison to other top-level athletes in various combat sports, this value was similar to those established in taekwondo athletes ${ }^{[18]}$, judo athletes ${ }^{[19]}$, and wrestlers ${ }^{[20]}$, but it was lower than those values reported in boxers ${ }^{[19]}$.

Mean HR elicited during international karate competition was $183 \pm 8$-bpm, which corresponded to approximately $91 \pm 3 \%$ of competitors' HRmax, suggesting that high demands are placed upon aerobic metabolism during competition. Comparable cardiovascular strain has been reported during simulated karate sparring matches (93\% HRmax) ${ }^{[6]}$, during kata bouts (94\% HRmax) ${ }^{[21]}$ and internationallevel taekwondo competition (93\%) ${ }^{[22]}$. This would suggest that the physiological demands are similar irrespective of karate modes, style of combat or level of competition. Thus, the hypothesis that official combat could be of "harder" intensity with respect to sparring training combat is wrong. It seems that the higher level of karate performance is to be found elsewhere than at the level of HR response.

Measurement of [ $\left.\mathrm{La}^{-}\right]$concentrations has been adopted as a simple method for determination of the role of the glycolytic metabolism in energy production during exercise. The mean post $\left[\mathrm{La}^{-}\right]$elicited during competition (i.e. $9.2 \mathrm{mmol} . \mathrm{L}^{-1}$ ) was higher than that found in previous studies (i.e., $7.7 \mathrm{mmol} . \mathrm{L}^{-1}$ ) during simulated karate competition ${ }^{[3]}$. Ravier et al ${ }^{[23]}$ have shown that $\left[\mathrm{La}^{-}\right]$in male karate athletes wes significantly higher in national than in international athletes after a supramaximal treadmill test. They concluded that the lower [ $\left.\mathrm{La}^{-}\right]$after exhaustive exercise in international level karate athletes might reflect a lower level of anaerobic energy supply or a more efficient lactate clearance. However, the non-specific task used limits the comparison with the present study's findings. The athletes of the present study have accumulated significantly more lactate after the fights compared with the athletes who participated in the study of Beneke et al ${ }^{[3]}$. Since the conditions of competition were different, it is possible that athletes' muscle demand required higher anaerobic energy than that used by the athletes tested by Beneke et al ${ }^{[3]}$. This difference might be also attributed to the different competition types. This would suggest that the level of competition influences anaerobic energy provision. Comparable anaerobic demands have been also reported during simulated taekwondo competition (i.e. 10.2 $\left.\pm 1.2 \mathrm{mmol} . \mathrm{L}^{-1}\right)$ and during official international taekwondo competition (i.e. $9.9 \pm 2.3$ mmol. $\mathrm{L}^{-1}$ ) ${ }^{[22,24]}$.

Beneke et al ${ }^{[3]}$ observed 5.9 \pm 1.6 mmol. $\mathrm{L}^{-1}$ net $\left[\mathrm{La}^{-}\right]$ increase after the first karate match of 3 minutes, followed by a decrease over the 3 subsequent matches, with a consequent significant reduction in the absolute contribution of the glycolytic metabolism. In the present study, $\left[\mathrm{La}^{-}\right]$increased significantly $(5.97 \pm 2.10$ mmol. $\mathrm{L}^{-1}$ ) from pre-combat to match 1 , which is quite similar to the value reported by Beneke et al ${ }^{[4]}$. However, in the present study it was not possible to determine the delta of [ $\left.\mathrm{La}^{-}\right]$between matches 1 and 2 or between matches 2 and 3 , because in-between measurements were not possible. The stability of [ $\left.\mathrm{La}^{-}\right]$ value can be explained by the important recovery time between matches in this official competition with $33.6 \pm 7.6 \mathrm{~min}$ for the first period between match 1 and 2 and $14.5 \pm 3.1$ min between match 2 and 3 . This would suggest that the physiological demands of karate competitors are sustained throughout the combat, providing the competitors with adequate time for recovery. This glycolytic demand during fighting 
activities and the unchanged concentrations of $\left[\mathrm{La}^{-}\right]$ between matches may suggest to study the rate of lactate before and after each match, and thus better understand its variation.

There was no HR increase over the course of the three phases of competition. This suggests that cardiovascular demands remained stable through the matches. This result is similar to that reported by Iide et $\mathrm{al}^{[6]}$, who observed a small variation in HR in two karate combat simulations, one of 2 min and another of 3 min duration. Conversely, for taekwondo, a significant increase in HR was observed across rounds' cardiovascular demand per round ${ }^{[25]}$. However, it is important to consider that in this previous study, the comparison was conducted between three rounds separated by only one min interval, while in the present study the interval between two successive matches was higher than $10 \mathrm{~min}$. Additionally, the percentage of time spent in each specific HR intensity zone was also unaltered between matches, which was not the case in other studies with taekwondo as an example ${ }^{[26]}$. The average percentage of time spent in intensity zone 5 (90-100\% HRmax) represented $74 \%$ of the total time of karate match and demonstrated a higher cardiovascular strain than previously reported in a taekwondo match $(>78 \%)^{[26]}$.

Another main finding of the present study was the significant relationships found between RPE, [ $\left.\mathrm{La}^{-}\right]$, and mean HR after matches in an international karate competition. Milanez et al ${ }^{[27]}$ found a higher significant correlation between RPE and mean [ $\left.\mathrm{La}^{-}\right]$ $(\mathrm{r}=0.96)$, and \%HRmax $(\mathrm{r}=0.91)$ in moderate intensity karate training sessions involving basic techniques (kihon) and sparring. Herman et al ${ }^{[28]}$ found significant relationships between objective physiological measures of aerobic demand $\left(\% \mathrm{VO}_{2} \max , \% \mathrm{HRmax}\right.$ and $\% \mathrm{HR}$ reserve) and RPE during continuous 30 min running or cycling bouts. In addition, these authors stated that these relationships were apparently weaker at higher exercise intensities, which support the present study's results. In the same way, Serrano et al ${ }^{[29]}$ reported that the recall of RPE of the whole effort performed in a judo competition was significantly related to maximal [La'] attained after the last fight. Additionally, the results of Perandini et al ${ }^{[30]}$ showed a significant correlation $(P<0.05)$ and high agreement $(\mathrm{r}=0.71)$ among training intensity distribution based on $\left[\mathrm{La}^{-}\right]$and RPE responses.

In the present study we found significant correlations between RPE and rest heart rate $(\mathrm{r}=0.60$; $P=0.004)$ and mean heart rate $(\mathrm{r}=0.64 ; P=0.02)$, suggesting that athletes with higher resting HR normally have a higher increase in the RPE in response to the combat and that RPE are probably influenced by the match cardiovascular response, as assessed by the heart rate during the competition.

To the best of our knowledge, the present study is the first to apply Foster's RPE-based approach to quantify internal TL during international karate competition and to demonstrate significant correlations between this method and other validated methods based on the HR response to exercise. The present study investigated the construct validity of sessionRPE as indicator of internal TL in elite Karate athletes. Specifically, the correlations (convergent validity) between session-RPE and two HR-based methods commonly considered as valid indicators of internal TL during competitions were determined. The three methods (objectives and subjective) monitored the same construct (i.e. TL or more precisely competitionload in the present study). In the present investigation, large correlations were found between session-RPE and HR-based methods (i.e. Banister's TRIMP, $\mathrm{r}=84$; $P<0.001 ; \quad$ Edwards TL, $\mathrm{r}=0.95 ; \quad P<0.01)$. The magnitude of correlations between session-RPE method and the HR-based methods were consistent with the study of Haddad et al ${ }^{[9]}$ in Taekwondo (i.e. Banister's TRIMP, $r$ values from 0.56 to 0.90; Edwards $\mathrm{TL}, \mathrm{r}$ values from 0.55 to 0.86 ). The correlations of the present study were slightly higher than those reported in the young Taekwondo competition (i.e. Ede Rwards TL, $\mathrm{r}=0.61 ; P<0.001 ; 95 \%$ CI: $0.47-0.72$ ). A possible explanation for the higher correlations in the present study could be that adults can better explain their RPE compared to young athletes ${ }^{[31]}$. In some cases, the correlations between session-RPE and Banister TRIMP were not consistent with the study of Perandini et al ${ }^{[30]}$, which showed a moderate correlation between session-RPE and Banister TRIMP ( $\mathrm{r}=0.52)$ and Edward $\mathrm{TL}(\mathrm{r}=0.64)$. This moderate correlation was probably observed because Banister TRIMP is a poor method to evaluate high-intensity exercise with significant 
anaerobic contribution, such as taekwondo. More recently, Campos et al ${ }^{[32]}$ hypothesized that karate may require a much higher percentage contribution of aerobic metabolism when compared with taekwondo. This difference may be due to the difference in kumite duration or the use of more upper limb techniques in karate compared with taekwondo. Similar results were found in studies that assessed steady-state endurance sport with a high aerobic contribution ${ }^{[8]}$.

In the present study, the magnitude of the association between session-RPE and HR-based methods was strong enough to provide confirmation that session-RPE method can be a valid alternative indicator for quantifying measures during official competition in elite karate athletes and may be a more reliable measure of exercise intensity when both anaerobic and aerobic systems are appreciably activated, such as during karate competition (as explained above).

A nearly perfect correlation was also observed between Banister TRIMP and Edwards TL during karate competition. This magnitude of correlation was similar to that reported by Haddad et al ${ }^{[11]}$ who demonstrated the convergent validity between these two objective methods based on HR for quantifying TL in young taekwondo athletes ( $\mathrm{r}=0.89 ; P<0.001 ; 95 \%$ CI: 0.86-0.91). This agrees with the findings of a previous study of Borresen and Lambert ${ }^{[8]}$ who found a correlation of $\mathrm{r}=0.98$ (95\% CI: 0.96-0.99) between total TL calculated using Banister TRIMP and Edwards TL (pooled data) in recreationally trained adults runners aged $30 \pm 5$ years.
One limitation of the present study is that the data was provided from only seven karate athletes (four male and three female). Thus, future investigations using larger samples and athletes with other characteristics must be carried out to confirm the conclusions in this study.

\section{CONCLUSION}

International karate competition elicited near-maximal cardiovascular responses and high [ $\left.\mathrm{La}^{-}\right]$concentrations. HR during competition was most frequently distributed between 90 and $100 \%$ of HRmax. Thus, the karate training should therefore include exercise bouts that sufficiently stimulate this exercise intensity zone. Based on the results of the present study, the RPE method is preferred to other methods based on HR and [La'] measurements due to its easy applicability and self-administration feature. Karate coaches could use the RPE-method to follow competition loads and consider it in their technical and tactical choice.

\section{ACKNOWLEDGMENTS}

The present study was supported by the "Ministère de l'Enseignement Supérieur et de la recherche Scientifique". The authors are grateful to all participants for their enthusiasm and commitment to the completion of this study.

Conflict of interests: None

\section{REFERENCES}

[1] Chaabene H, Hachana Y, Franchini E, et al. Physical and physiological profile of elite karate athletes. Sports Med 2012;42:829-43.

[2] Lehmann G, Jedliczka G. Untersuchungen zur Bestimmung und Entwicklung eines sportartspezifischen konditionellen Anforderungsprofils im Hochleistungstraining der Sportart Karate-Kumite. / Investigations on the determination and development of a sport-event-specific profile of the physical requirements in high-performance training for the sport of karate-kumite. Leistungssport 1998;28:56-61.

[3] Beneke R, Beyer T, Jachner C, et al. Energetics of karate kumite. Eur J Appl Physiol 2004;92:518-23.

[4] Glaister M. Multiple sprint work : physiological responses, mechanisms of fatigue and the influence of aerobic fitness. Sports Med 2005;35:757-77.

[5] Gilles R, Jean-Denis R. Ammoniaque et lactate plasmatiques accumulés en combat de karate. Science et Motricité 2003;49:83-95. [In France] 
[6] Iide K, Imamura H, Yoshimura Y, et al. Physiological responses of simulated karate sparring matches in young men and boys. $J$ Strength Cond Res 2008;22:839-44.

[7] Foster C, Florhaug JA, Franklin J, et al. A new approach to monitoring exercise training. J Strength Cond Res 2001;15:109-15.

[8] Borresen J, Lambert MI. Quantifying training load: a comparison of subjective and objective methods. Int J Sports Physiol Perform 2008;3:16-30.

[9] Haddad M, Chaouachi A, Castagna C, et al. The construct validity of session RPE during an intensive camp in young male Taekwondo athletes. Int J Sports Physiol Perform 2011;6:252-63.

[10] Impellizzeri FM, Rampinini E, Coutts AJ, et al. Use of RPE-based training load in soccer. Med Sci Sports Exerc 2004;36:1042-7.

[11] Haddad M, Chaouachi A, Castagna C, et al. The convergent validity between two objective methods for quantifying training load in young taekwondo athletes. J Strength Cond Res 2012;26:206-9.

[12] Edwards S. High performance training and racing. In: Edwards S, ed. High performance training and racing. Sacramento, CA: Feet Fleet Press 1993; Pp:113-23.

[13] Haddad M, Chaouachi A, Castagna C, et al. Validity and psychometric evaluation of the French version of RPE scale in young fit males when monitoring training loads. Sci Sports 2013;28: e29-e35.

[14] Banister E. Modeling elite athletic performance. In: Green H, McDougal J, Wenger H (eds). Modeling Elite Athletic Performance. Champaign: Human Kinetics 1991; Pp:403-24:

[15] Imamura H, Yoshimura Y, Uchida K, et al. Maximal oxygen uptake, body composition and strength of highly competitive and novice karate practitioners. Appl Human Sci 1998;17: 215-8.

[16] Imamura H, Yoshimura Y, Uchida K, et al. Heart rate, blood lactate responses and ratings of perceived exertion to 1,000 punches and 1,000 kicks in collegiate karate practitioners. Appl Human Sci 1997;16:9-13.

[17] Ravier G, Grappe F, Rouillon JD. Application of force-velocity cycle ergometer test and vertical jump tests in the functional assessment of karate competitor. J Sports Med Phys Fitness 2004;44:349-55.

[18] Heller J, Peric T, Dlouha R, et al. Physiological profiles of male and female taekwon-do (ITF) black belts. J Sports Sci 1998;16:243-9.

[19] Franchini E, Del Vecchio FB, Matsushigue KA, et al. Physiological profiles of elite judo athletes. Sports Med 2011;41:147-66.

[20] Yoon J. Physiological profiles of elite senior wrestlers. Sports Med 2002;32:225-33.

[21] Doria C, Veicsteinas A, Limonta E, et al. Energetics of karate (kata and kumite techniques) in top-level athletes. Eur J Appl Physiol 2009;107:603-10.

[22] Estevan I, Alvarez O, Falco C, et al. Impact force and time analysis influenced by execution distance in a roundhouse kick to the head in taekwondo. J Strength Cond Res 2011;25:2851-6.

[23] Ravier G, Dugue B, Grappe F, et al. Maximal accumulated oxygen deficit and blood responses of ammonia, lactate and pH after anaerobic test: a comparison between international and national elite karate athletes. Int J Sports Med 2006;27:810-7.

[24] Bouhlel E, Jouini AGN, Nefzi A, et al. Heart rate and blood lactate responses during Taekwondo training and competition. / Evolution de la frequence cardiaque et de la lactatemie au cours de l'entrainement et de la competition de Taekwondo. Sci Sports 2006;21: 285-90.

[25] Bridge CA, Jones MA, Drust B. Physiological responses and perceived exertion during international Taekwondo competition. Int J Sports Physiol Perform 2009;4:485-93.

[26] Capranica L, Lupo C, Cortis C, et al. Salivary cortisol and alpha-amylase reactivity to taekwondo competition in children. Eur $J$ Appl Physiol 2012;112:647-52.

[27] Milanez VF, Lima MCS, Gobatto CA, et al. Correlates of session-rate of perceived exertion (RPE) in a karate training session. Sci Sports 2011;26:38-43.

[28] Herman L, Foster C, Maher M, et al. Validity and reliability of the session-RPE method for monitoring exercise training intensity. S Afr J Sports Med 2006;18:14-7.

[29] Serrano MA, Salvador A, Gonzalez-Bono EG, et al. Relationships between recall of perceived exertion and blood lactate concentration in a judo competition. Percept Mot Skills 2001;92:1139-48.

[30] Perandini LA, Siqueira-Pereira TA, Okuno NM, et al. Use of session RPE to training load quantification and training intensity distribution in taekwondo athletes. Sci Sports 2011;27:e25-e30.

[31] Groslambert A, Mahon AD. Perceived exertion : influence of age and cognitive development. Sports Med 2006;36: 911-28.

[32] Campos FA, Bertuzzi R, Dourado AC, et al. Energy demands in taekwondo athletes during combat simulation. Eur J Appl Physiol 2012;112:1221-8. 